\title{
Conditioning (habit growth) in the absence of CRs
}

KENMETH W. SPENCE ANO EDWARD DEAUX

UNIVERSITY OF TEXAS

The assumption that conditioning (growth of $\mathrm{H}$ ) developed in $S s$ who gave no eyelid CRs in an initial series of 10 reinforced trials was supported by data which showed that a subsequent test involving a difference in UCS intensity (level of D) led to a difference in level of response to the CS.

The Hull-Spence theoretical model of classical conditioning (cf., Spence, 1956) assumes that each reinforced trial, i.e., CS-UCS presentation, results in an increment in the associative or habit strength $(\mathrm{H})$ of the $\mathrm{CS}$ to evoke the $\mathrm{CR}$. The presence of $\mathrm{H}$, however, does not assure the occurrence of a $\mathrm{CR}$, and an $\mathrm{S}$ may fail, especially in the early stages of conditioning, to give any CRs in spite of the theoretically increasing $\mathrm{H}$. One condition for the failure of a response is that the strength of the excitatory potential $(E=H \times D)$ be below the threshold value (L) necessary for response elicitation. This is most likely to be the case when the value of $\mathrm{H}$ is small and/or the drive level (D) resulting from the UCS intensity is low. But even when E>L, a CR may not occur because the momentary excitatory potential $(\dot{E})$ is, due to the value of oscillatory inhibition $\left(\mathrm{I}_{\mathrm{O}}\right)$ present on the trial occasion, below $\mathrm{L}$, i.e., $\dot{E}=\left(E-L_{O}\right)<L$.

The present experiment was primarily concerned with testing the model's implication that Ss who give no CRs in an initial series of 10 conditioning trials nevertheless develop $\mathrm{H}$ for the $\mathrm{CR}$. The test involved increasing $D$ in one group of such Ss with several presentations of a substantially stronger puff alone and then giving a test series of nonreinforced (CS-alone) trials under this increased drive level. The increment in $D$ and consequent increase in $E$, if sufficiently great, should produce a level of responding in these Ss which is higher than that of a comparable group of Ss in which the puff intensity was not changed. A control group was employed to rule out the possibility that the increase in response frequency with increased $D$ is not merely due to an increase in spontaneous blinking. Method

The apparatus for recording the response and controlling the time relations of the stimulus events was similar to that used in the Iowa Laboratory of the senior author (cf., Spence \& Taylor, 1951). The equipment used in the probability learning (masking) task, in which the conditioning was imbedded, is described by Spence, Homzie, \& Rutledge (1964). The CS consisted of a $500 \mathrm{cps}, 70 \mathrm{~dB}$ tone with a duration of $350 \mathrm{msec}$. presented over a continuous white-noise background of $60 \mathrm{~dB}$ intensity. The UCS was a puff of compressed air of $50 \mathrm{msec}$. duration, delivered to the right eye through a .062 in. diameter orifice. Puff intensity, measured at the eye, was 0.4 or $3.0 \mathrm{psi}$ depending on the experimental condition. The CS-UCS interval was $300 \mathrm{msec}$, and both stimuli terminated together.

The CS and UCS were given between the presentation of a visual signal that instituted each game trial and the onset of one of two information lights that terminated the trial. Temporally, the CS onset followed the offset of the $500 \mathrm{msec}$. signal light by $1.5 \mathrm{sec}$. on half the trials and by 3.0 sec. on the other half. The time between the CS offset and the onset of the information light (700 msec.), the information light duration $(750 \mathrm{msec}$.) and the interval between offset of the latter and the signal for the next game trial $(3600 \mathrm{msec}$.) were constant on all trials. Interspersed among conditioning trials were an equal number of game alone trials (GA) in which the CS and UCS were not present. The trial events were so arranged that the ITI between conditioning trials ranged between 9.5 and $31.5 \mathrm{sec}$. and averaged approximately $20 \mathrm{sec}$.

Eighty-nine men and 51 women students from an introductory psychology course were assigned to one of three groups, designated according to puff intensity as Weak-Strong (WS), Weak-Weak (WW) and Control Weak-Strong (CWS) with Ns of 50,42 , and 48 , respectively. After four preliminary trials consisting of three with the CS alone and one with the UCS alone, the first of three experimental phases was begun. During this phase Groups WW and WS received 10 CS-UCS paired trials followed by one CS-alone trial. Randomly interspersed among these trials were $10 \mathrm{GA}$ trials. Group CWS received $10 \mathrm{CS}-a$ lone and 10 UCS-alone trials in Phase I with no GA trials. Phase II was the same for all Ss, consisting of five UCS-alone trials randomly interspersed with five GA trials. In Phase III all three groups received 10 nonreinforced CS trials intermixed with 10 UCS-alone trials.

The UCS intensity for all three groups in Phase I was $0.4 \mathrm{psi}$, and for Group WW this puff strength was maintained throughout all three phases of the experiment. Groups WS and CWS, however, received a UCS of 3.0 psi intensity in Phases II and III. The design, therefore, involves the same stimulus presentations for Groups WW and WS, with different puff strengths during Phases II and III, and the same puff strengths for Groups WS and CWS, with the latter receiving no conditioning (i.e., paired CS-UCS) trials in Phase I. A CR was counted whenever the recording pen showed a deflection of $1 \mathrm{~mm}$ or more in the interval 100-310 msec. following the onset of the CS.

\section{Results}

The primary data of concern are those provided by Ss who did not give any responses in the 10 trials of Phase I. Group WS contained 25 such Ss, Group WW 17 


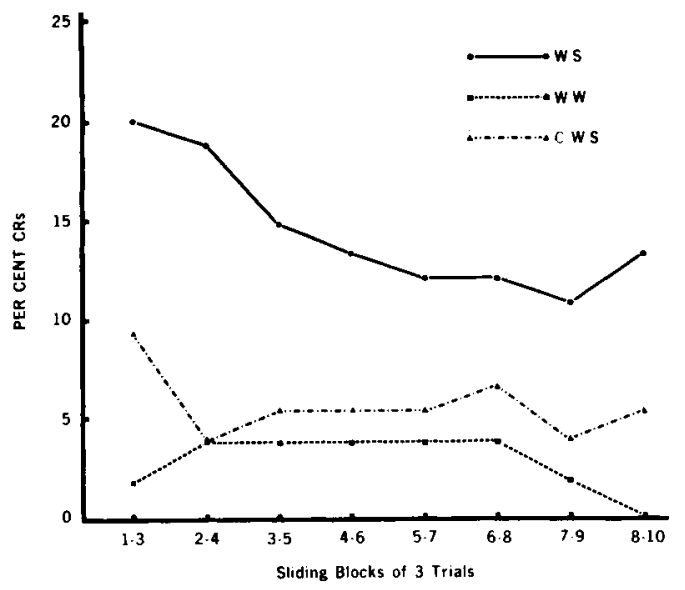

Fig. 1. Percent CRs in sliding blocks of 3 trials of Phase III for Ss of groups WS, WW, and C-WS who gave no CRs in Phase I

and Group CWS 25. It should be noted that since spontaneous eyeblinks are indistinguishable from CRs, they are counted as responses. Inclusion in the zero response category of $\mathrm{Ss}$, then, is a function not only of a zero or low level of conditioning $(\mathrm{H})$, low drive level (D) and a low spontaneous blink rate, but also of the fact that, by chance, no spontaneous blinks happened to occur in the brief $210 \mathrm{msec}$. period in which the responses are recorded on any of the 10 trials. Some evidence that the zero responders had a somewhat lower blink rate than did Ss who gave responses in Phase I is shown by the fact that they gave fewer $r \epsilon$ sponses on the five trials of Phase II.

Figure 1 presents the data obtained in Phase III for the Ss that gave no responses in Phase I. As may be seen, in agreement with the implication of our theoretical model, Ss (Group WS) who had been conditioned originally with the weak UCS and then tested in Phase III with the strong UCS showed a substantial increase in the frequency of their responses. ${ }^{2}$ This increase is to be compared first with that of Group WW, which had the weak UCS in Phases II and III and showed a small, but insignificant increase in the level of responding in Phase III. Presumably this slight rise represents an increase, by chance, in the number of random blinks and possibly, the occurrence of some CRs by virtue of low $I_{O}$ values. However, the increase is clearly much less than that of Group WS, and the difference between the two groups' performance levels over all 10 trials was significant $(t=2.87, p<.01)$. This finding is in accord with the prediction based on our theoretical model, including the initial assumption that $\mathrm{H}$ was developed in $\mathrm{Ss}$ that gave no responses in the initial conditioning phase. If, however, the higher response level of Group WS reflected only an increased rate of spontaneous bliıiking due to the more noxious puff, one would not need to assume the development of $H$ in these Ss in Phase $I$. This alternative possibility is not supported by the control group's performance, which is significantly below that of Group WS $(t=2.33$, $\mathrm{p}<.05)$.

Further evidence against this possibility is the number of responses given by the Ss of Group WS in the UCS-alone trials of Phase HI. Since the CS was not present in this phase, responses occurring in the recording period must be random blinks and not CRs. As in the case of Group CWS, the level of spontaneous responding in Group WS rose, on Trial 2 following the first strong puff, to $24 \%$ and then dropped successively to 16,8 , and $4 \%$ on the subsequent three trials. The latter value is at about the same level of responding as Group WW in Phase III.

While the present experiment was not designed to test the more recent statistical learning models, its findings do have a bearing on the simple two-state, one-element model which, in his initial enthusiasm for these Markovian type models, Estes (1960) believed adequately described human eyelid conditioning data. The present results are quite contrary to the implications of this model. Since the Ss of Group WS gave no CRs in Phase 1 , they were clearly in a nonconditioned state and should not have been expected to give other than random blinks in Phase III, a prediction refuted by their performance being higher than the control group's. While the three-state, two-element model is able to explain the occurrence of CRs in Phase III over above random blinks, a satisfactory account is lacking as to why increased drive leads to heightened performance.

\section{References}

Estes, W. K. Learning theory in the new "mental chemistry." Psychol. Rex., 1960, 67, 207-223.

Spence, K. W. Bihatior theory and conditioning. New Haven: Yale University Press, 1956

Spence, K. W.. Homzie, M. J.. \& Rutledge. F. F. Extinction of the human evelid $C R$ as a function of the discriminability of the change from acquisition to extinction. $J$. crp. Psychol., 1964, $67,545-552$

Spence, K. W., \& Taylor. J. A. Anxiety and strength of UCS as determiners of the amount of eyelid conditioning. $J$. c.xp. Psychol., 1951, 42, 183-188.

\section{Notes}

1. This research was supported by a project concerned with human conditioning under contract Nonr-375(18) between the University of Texas and the Office of Naval Research and by a Public Health Service fellowship (28,642-01) from N.I.M.H. to the second author. The authors wish to thank Abigail Capaldi and John Tyler for their assistance in collecting data.

2. That the true mean performance level in the first 3 trials of Phase III is greater than zero is supported by the fact that the lower limit of the .99 confidence interval about this mean is $6.09 \%$ CRs. 